\title{
Quantitative mapping of trace elements in agate using LA-ICP-MS
}

\author{
Chan-Soo Park ${ }^{1}$, Hyung Seon Shin ${ }^{1}$, Keewook Yi ${ }^{1}$, Hana Cho ${ }^{1}$ and Yoonsup Kim ${ }^{2 *}$
}

\begin{abstract}
Background: Laser ablation inductively coupled plasma mass spectrometry (LA-ICP-MS) is an optimized technique for the quantitative mapping of trace elements on geological materials. Agate is an aggregate of microcrystalline silica showing a variety of colorful bands due to the species and concentrations of transition metals and is thus an appropriate sample to test the availability, efficiency, and detection limit of LA-ICP-MS trace element mapping.

Methods: Two fortification agate samples selected for elemental mapping are characterized by the colorful and bluish banding layers, respectively. The colorful agate sample consists mainly of two growth zones varying in color from pale orange-red brown to gray tones, whereas the blue agate sample simply shows alternating blue and white bands. Two different types of mineral inclusions, Fe oxide/hydroxide and hollandite $\left(\mathrm{Ba}\left(\mathrm{Mn}_{6}^{4+} \mathrm{Mn}_{2}^{3+}\right) \mathrm{O}_{16}\right)$, were identified in the inner and outer halves of the former sample, respectively. The distribution patterns of eight trace elements in these samples, including $\mathrm{Al}, \mathrm{Co}, \mathrm{Cr}, \mathrm{Cu}, \mathrm{Fe}, \mathrm{Mn}, \mathrm{Ni}$, and Ti, were investigated, using both electron microprobe and LA-ICP-MS.

Results: Aluminum and Fe are the most abundant trace elements in both agate samples up to $5000 \mathrm{ppm}$ although their concentrations in the colorful agate sample are an order of magnitude higher than those in the blue agate sample. The concentrations of other elements in the agate samples are several parts per million levels. The quantitative maps of the colorful agate sample have shown that Fe was mainly distributed in the inner half, but Al, $\mathrm{Cu}$, and $\mathrm{Mn}$ in the outer half. In particular, Fe and $\mathrm{Mn}$ were primarily concentrated as small spots. On the other hand, the oscillatory zoning patterns are apparent in the quantitative maps of the blue agate sample, showing a correlative relationship between $\mathrm{Al}$ and Ti but an antithetic relationship between $\mathrm{Al}$ and $\mathrm{Fe}$. The $\mathrm{Al}$ and $\mathrm{Fe}$ distribution patterns of the colorful agate sample are reproduced in the Al Ka and Fe Ka X-ray maps, but not clear in blue agate.
\end{abstract}

Conclusions: Quantitative elemental maps using LA-ICP-MS are privileged to visualize trace elements distributions.

Keywords: LA-ICP-MS, Quantitative mapping, Trace element distribution, Agate

\section{Background}

Inductively coupled plasma mass spectrometry (ICPMS) has become the most widely accepted analytical technique for simultaneously measuring a range of trace elements at variable concentration levels (Durrant 1999; Günther and Heinrich 1999; Günther et al. 2000; Sylvester 2001a; Heinrich et al. 2003). Laser ablation (LA) system is powerful and versatile for in situ microsampling of solid materials including geological samples particularly when it is attached to ICP-MS (e.g., Jackson et al. 1992; Norman

\footnotetext{
*Correspondence: yoonsup@cbnu.ac.kr

${ }^{2}$ Department of Earth and Environmental Sciences, Chungbuk National

University, Cheongju 362-763, Republic of Korea

Full list of author information is available at the end of the article
}

et al. 1996, Günther et al. 1997; Jeffries et al. 1998; Niemax 2001; Heinrich et al. 2003; Günther and Hattendorf 2005; Large et al. 2009; Koenig et al. 2009; Ulrich et al. 2009). The development and application of laser ablation inductively coupled plasma mass spectrometry (LA-ICP-MS) have grown with a dramatic rate, and in situ analyses for elemental abundances and isotopic compositions are now performed routinely in numerous laboratories worldwide.

In addition to LA-ICP-MS, both ion and electron microprobes are commonly used for in situ analysis of trace elements (Müller et al. 2003). An electron microprobe has advantages of the smallest sampling volume and well-established data reduction procedures as well
Springer

(c) 2015 Park et al. Open Access This article is distributed under the terms of the Creative Commons Attribution 4.0 International License (http://creativecommons.org/licenses/by/4.0/), which permits unrestricted use, distribution, and reproduction in any medium, provided you give appropriate credit to the original author(s) and the source, provide a link to the Creative Commons license, and indicate if changes were made. 
as quantitative calibration methods, but extreme care is required for elements at very low abundances. In many cases, even long counting times coupled with a detailed background characterization may not achieve the required sensitivity of a trace element (Müller et al. 2003). Ion microprobe has the main strength on both high sensitivity and small sampling volume. However, the severe matrix effect in this technique commonly prevents us from quantitative analyses in the absence of appropriate standard materials (Hinton 1990). LA-ICP-MS analyses combine the strength of the above techniques: relatively straightforward calibration procedures with a low detection limit. A glass reference sample is applicable to the quantitative analyses of trace elements for different types of materials with acceptable uncertainties. However, LAICP-MS has relatively poorer spatial resolution and requires relatively larger sampling volumes than both electron and ion microprobes (Woodhead et al. 2007).

The quantitative mapping of trace elements in geological samples has been facilitated by LA-ICP-MS (Treble et al. 2003; Fairchild et al. 2006; Montagna et al. 2007). It is also possible with other microanalytical techniques such as ion microprobe, proton-induced X-ray emission (PIXE), and synchrotron X-ray fluorescence (Woodhead et al. 2007; Ulrich et al. 2009). In contrast to the above methods, LA-ICP-MS trace element mapping is the only technique performing at low limits of detection for a wide range of elements in a relatively short acquisition time. The application of quantitative element distribution maps using LA-ICP-MS has been accelerated with the development of analytical protocol and easy-to-use software such as Iolite (Woodhead et al. 2007; Ulrich et al. 2009).

Agate is an aggregate of various forms of microcrystalline silica, mainly chalcedony, and is generally formed by chemical precipitation in rock cavities (Götze et al. 2001). Chalcedony occurs commonly in a semitransparent or translucent state, with waxy luster, and varies widely in color, in contrast to colorless, transparent microcrystalline quartz (Polk 2012). Transition metals incorporated during the precipitation color agates (Götze et al. 2001; Möckel et al. 2009). The species and concentration of transition metals in agate are commonly reflected by its rhythmic color banding (Heaney and Davis 1995). The shade of color is further modified when these elements work in combination. Thus, agate is an appropriate sample to test the availability, efficiency, and detection limit of LA-ICP-MS trace element mapping. In this study, the distribution patterns of trace elements in two agates were investigated, using LA-ICPMS, for demonstrating (1) the advantages of LA-ICP-MS trace element mapping through a correlation between the colors and concentrations of trace elements in the agate samples and (2) the analytical uncertainties and detection limits on the analyses of trace elements best optimized in the study.

\section{Sample descriptions}

Two fortification agate samples were selected for elemental mapping because of their sub-radial growth towards the center. Both samples are oval in shape with approximately 50-mm-long major axes and are characterized by the colorful and bluish banding layers, respectively. The colorful agate sample is mainly divided into two growth zones: the inner and outer halves on the basis of $\sim 0.2-\mathrm{mm}$-thick white band (Fig. 1a). The inner half shows varying colors, from pale orange to red brown whereas the outer half is generally composed of color bands in gray tones. On the other hand, the blue agate sample simply shows alternating blue and white bands (Fig. 1b). Using an optical microscope, numerous small mineral inclusions were observed in the inner and outer halves of the former sample. Two different types of mineral inclusions were identified under scanning electron microscopy. In the inner half, Fe oxide/hydroxide is mainly distributed as clusters of oriented crystallites (up to $10 \mu \mathrm{m}$ long) (Fig. 2a) whereas mineral inclusions in the outer half are mainly $\sim 10-\mu \mathrm{m}$-long hollandite $\left(\mathrm{Ba}\left(\mathrm{Mn}_{6}^{4+} \mathrm{Mn}_{2}^{3+}\right) \mathrm{O}_{16}\right)$ (Fig. 2b). On the other hand, no mineral inclusions were observed in the blue agate

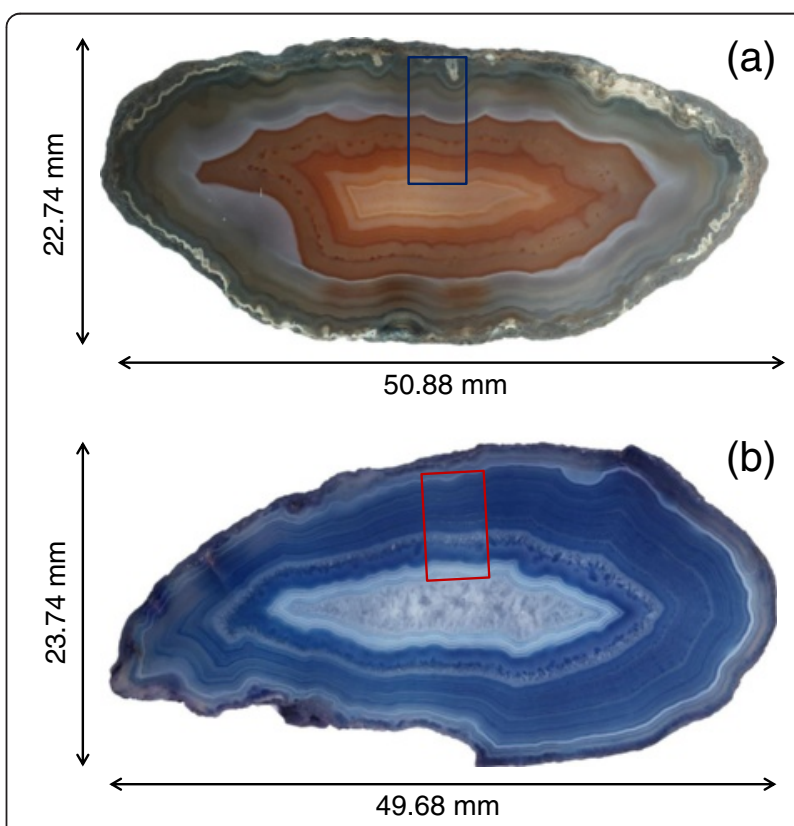

Fig. 1 Two fortification agate samples. They are oval in shape with approximately 50-mm-long major axes and are characterized by $\mathbf{a}$ colorful and $\mathbf{b}$ bluish banding layers, respectively. The former varies in color, from gray through orange and red to brown towards the center. On the other hand, the latter consists of bluish chalcedony alternating with white microcrystalline quartz. Open rectangles represent the areas of ablation 

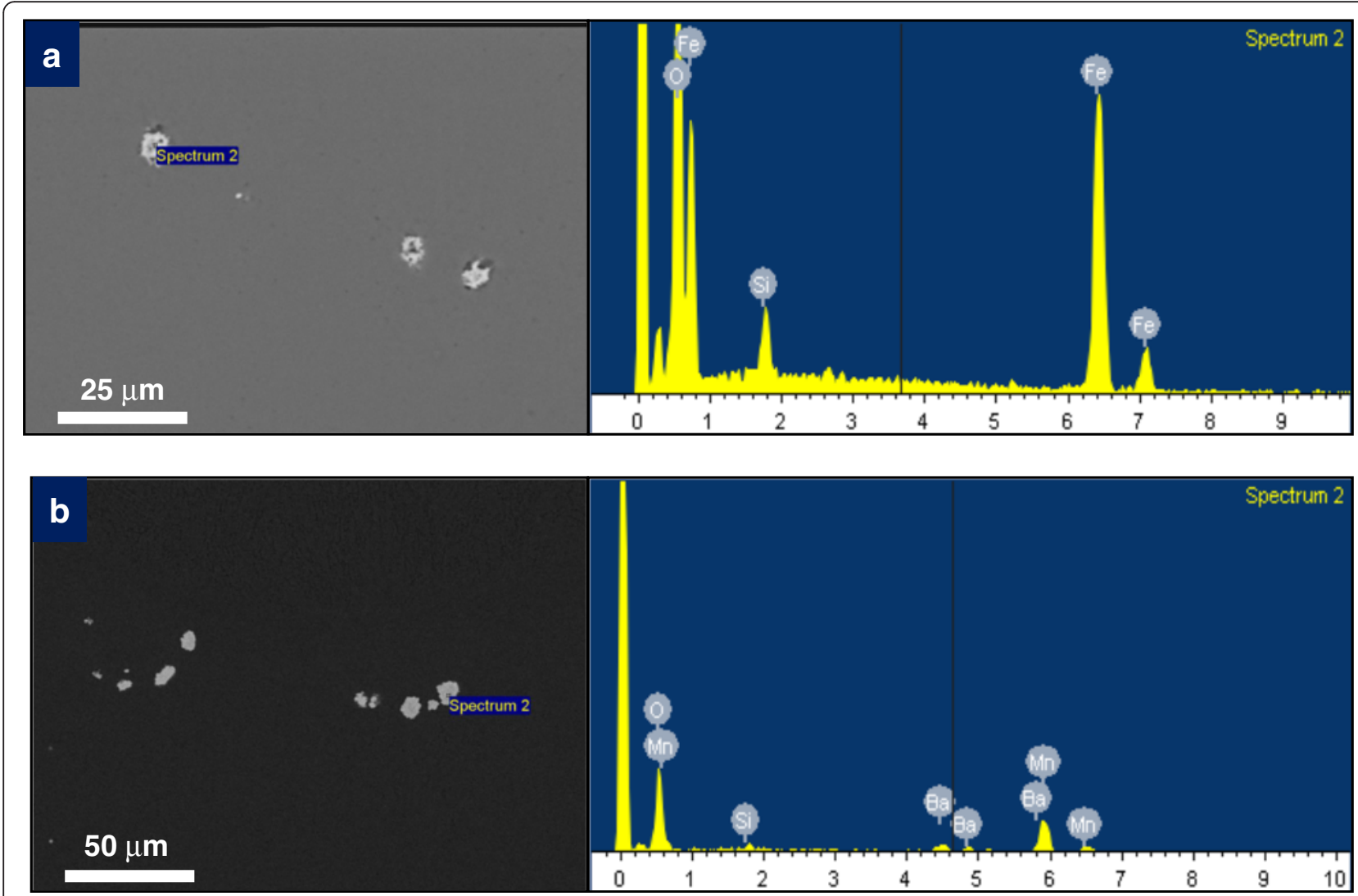

Fig. 2 Back-scattered electron images of a Fe oxide/hydroxide and $\mathbf{b}$ hollandite inclusions in agate, together with the corresponding EDS spectra

sample. The ablated area of each sample is represented by an open rectangle (Fig. 1a, b)

\section{Methods}

Qualitative mapping was carried out, using a Shimadzu 1600 electron microprobe equipped with wavelengthdispersive spectrometers (WDS) at the Jeonju branch of Korea Basic Science Institute (KBSI), by measuring intensities of the $\mathrm{Al} \mathrm{K \alpha}$, Co $\mathrm{K} \alpha, \mathrm{Cr} \mathrm{K} \alpha, \mathrm{Cu} \mathrm{K} \alpha$, Fe $\mathrm{K} \alpha, \mathrm{Mn}$ $\mathrm{K} \alpha$, Ti $K \alpha$, and Ni K $\alpha$ characteristic X-ray lines considered as potential chromophores in agate (Table 1). The analytical conditions were under the instrumental settings

Table 1 The correlation between the chemical composition and color of agate bands

\begin{tabular}{ll}
\hline Chemical composition & Color \\
\hline Iron oxide & Red, brown, black, green \\
Manganese & Pink, violet, black \\
Chromium & Green, yellow, red \\
Titanium & Blue \\
Cobalt & Red \\
Nickel & Green \\
Copper & Red, blue, green \\
\hline
\end{tabular}

at $15 \mathrm{keV}$ accelerating voltage, $1 \mu \mathrm{m}$ beam size, and $20 \mathrm{nA}$ current with $50 \mathrm{~ms}$ dwell time per pixel. Quantitative mapping was carried out, using a New Wave UP213 Nd:YAG laser ablation system attached to a Thermo X Series 2 quadrupole ICP-MS in the ICP-MS laboratory of KBSI. A series of parallel line scans was combined to image trace elemental maps. This method was superior to a mosaic of spot analyses because no interpolation between the spot analyses was necessary. Moreover, downhole fractionation was minimized in the method, and acquisition time was significantly saved. The $10-\mathrm{Hz}$ repetition rate and $55-\mu \mathrm{m}$ spot size of laser beam were used because the stability and intensity of ion signals as well as spatial resolution of images were best optimized at the condition (Fig. 3). Lines were scanned at $10 \mu \mathrm{m} / \mathrm{s}$ speed with $60-\mu \mathrm{m}$ spacing between adjacent line scans. The common quadrupole and imaging parameters used in the study are listed in Table 2.

NIST612 SRM glass was used as the external standard and ${ }^{29} \mathrm{Si}$ as the internal standard assuming stoichiometric quartz. The oxidation rate was monitored using the $\mathrm{ThO}^{+} / \mathrm{Th}^{+}$ratios of the external standard and was maintained below $1 \%$ during the analyses. The data reduction and image processing of chemical data were conducted with Iolite software (Hellstrom et al. 2008; 


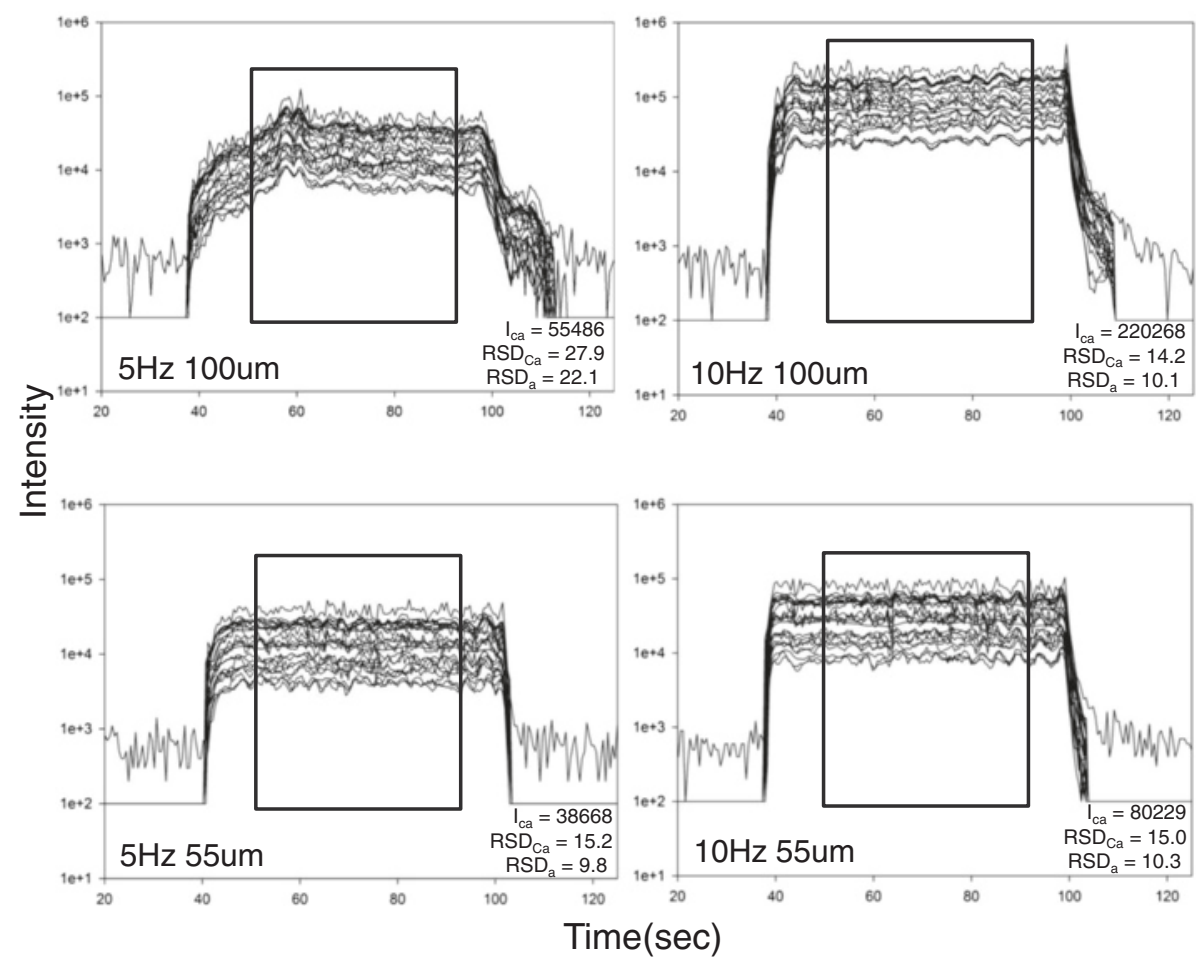

Fig. 3 Signal intensities and signal stabilities depending on the experimental conditions (repetition and spot size) during line scanning. NIST 612 glass was used for determining the optimal measurement conditions

Ulrich et al. 2009; Paton et al. 2011). The main advantage of this software is its capability to render line scans into quantitative element distribution images. Outlier rejection was applied to each line scan based on a $2 \sigma$ threshold. The dwell times for each trace element were $10 \mathrm{~ms}$ per analyte.

The accuracy of line analyses was estimated against two USGS microchemical standard materials (GSD-1G and BHVO-2G), using the above analytical conditions. The former reference material has a relatively constant concentration level $(\sim 54 \mathrm{ppm})$ for all trace elements,

Table $\mathbf{2}$ LA-ICP-MS instrument settings

\begin{tabular}{ll}
\hline RF power $(\mathrm{W})$ & 1200 \\
Ar nebulizer flow $(\mathrm{L} / \mathrm{min})$ & 0.73 \\
Ar auxiliary gas $(\mathrm{L} / \mathrm{min})$ & 0.85 \\
Ar cooling gas $(\mathrm{L} / \mathrm{min})$ & 13.5 \\
Laser wavelength $(\mathrm{nm})$ & 213 \\
$\mathrm{He}$ carrier gas $(\mathrm{L} / \mathrm{min})$ & 0.70 \\
$\mathrm{ThO}^{+} / \mathrm{Th}^{+}(\%)$ & $<1$ \\
Repetition rate $(\mathrm{Hz})$ & 10 \\
Energy density $\left(\mathrm{J} / \mathrm{cm}^{2}\right)$ & 11 \\
Dwell time $(\mathrm{ms})$ & 10 \\
Scan speed $(\mu \mathrm{m})$ & 10 \\
Beam size $(\mu \mathrm{m})$ & 55 \\
\hline
\end{tabular}

whereas the latter has a range of concentrations of trace elements from 0.3 up to $163 \mathrm{ppm}$. Concentrations of 20 trace elements were measured within $20 \%$ error estimates, with respect to the reference values of GSD-1G and BHVO-2G (Fig. 4). In the case of GSD-1G, the RSD values were calculated within $5 \%$ in almost all the elements. For BHVO-2G, however, the RSD values has increased with decreasing concentrations of the trace elements: the RSD values less than $5.5 \%$ for trace elements over $10 \mathrm{ppm}$, the RSD range of $5.9 \sim 8.9 \%$ for trace elements between 4 and $10 \mathrm{ppm}$, and the RSD range of $10 \sim 20 \%$ for trace elements less than $4 \mathrm{ppm}$. The coefficient of determination $\left(R^{2}\right)$ for a linear relationship between the measured and reference concentrations of GSD-1G and BHVO-2G was calculated as 0.811 and 0.9993 , respectively.

\section{Results}

\section{Colorful agate}

Aluminum and Fe were the most abundant trace elements in the colorful agate sample, up to 5000 and $4000 \mathrm{ppm}$, respectively, whereas $\mathrm{Cu}, \mathrm{Mn}$, and $\mathrm{Co}$ were minor, less than 200, 3, and $5 \mathrm{ppm}$, respectively. The heterogeneous distribution of trace elements in the sample was shown in four quantitative maps of $\mathrm{Al}, \mathrm{Fe}, \mathrm{Cu}$, and $\mathrm{Mn}$ (Fig. 5). Aluminum concentration was particularly high in the outer half characterized by grayish color 

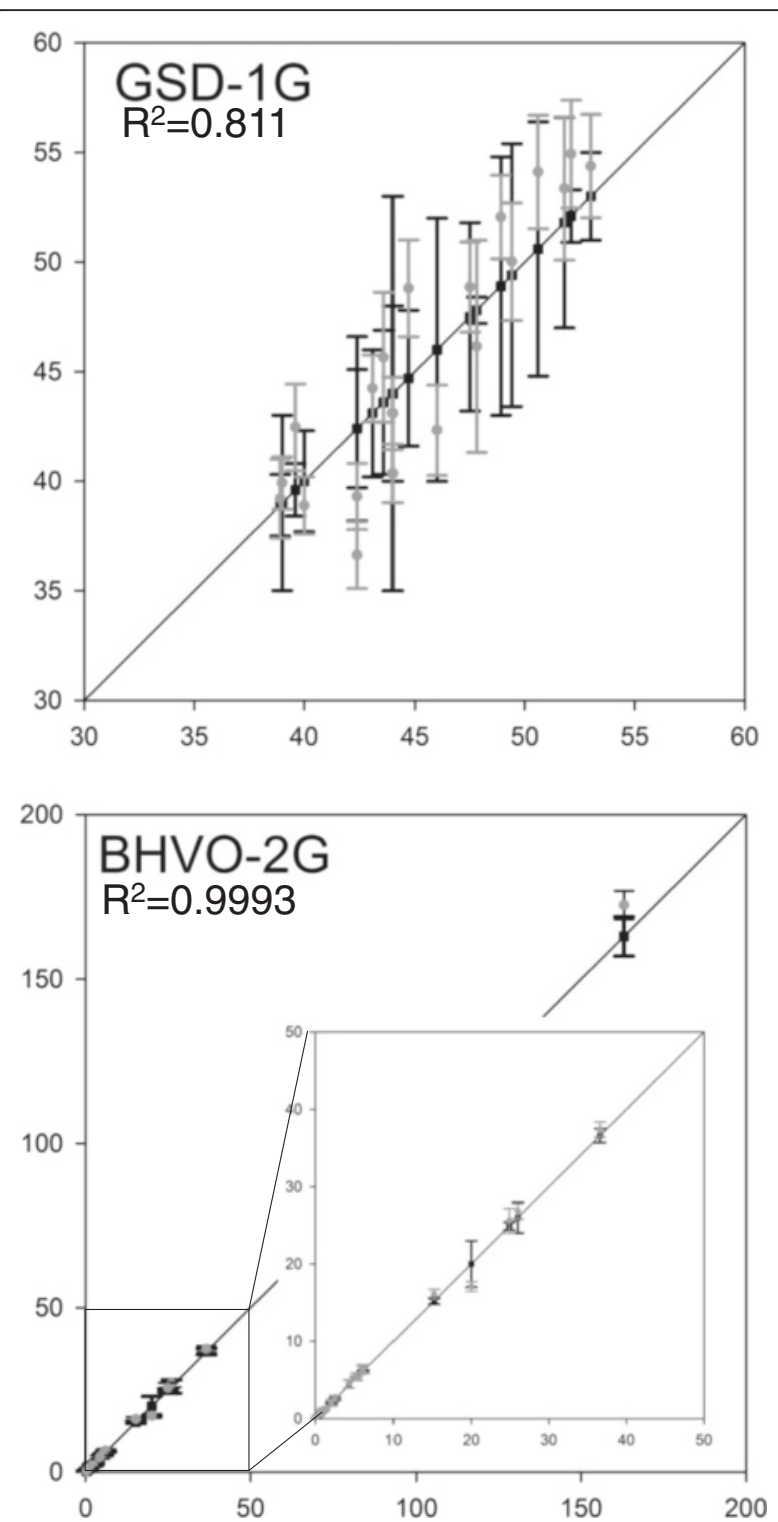

Fig. 4 Accuracy of line analyses of LA-ICP-MS in the study. USGS RMS (GSD-1G, BHVO-2G) were used for estimating the accuracy of line analyses. Vertical bars with squares are error ranges of the reference materials and those with circles are measured uncertainties

(Fig. 5a, b). The element was also concentrated at narrow bands and small spots in the middle part although it was generally absent in the inner half. On the other hand, several Fe-rich bands as well as many Fe-rich small spots were observed in the inner half (Fig. 5a, c). The distribution of $\mathrm{Cu}$ and $\mathrm{Mn}$ in the sample was similar to that of $\mathrm{Al}$ although these elements were concentrated mainly as small spots (Fig. 5d, e). In the X-ray maps, only $\mathrm{Al}$ and Fe showed the heterogeneous elemental distribution of colorful agate sample (Fig. 5f, g). Their distribution patterns resembled those of equivalent quantitative maps, but the boundaries of narrow bands and the overall background levels were blurred and increased, respectively.

\section{Blue agate}

Aluminum and Fe were also the most abundant trace elements in the blue agate sample, up to 400 and $100 \mathrm{ppm}$, respectively, whereas $\mathrm{Mn}$ and $\mathrm{Ti}$ were minor, less than 15 and $1 \mathrm{ppm}$, respectively. Heterogeneous elemental distribution was observed in the $\mathrm{Al}, \mathrm{Fe}$, and $\mathrm{Ti}$ quantitative maps of the blue agate sample (Fig. 6). All the elements were concentrated as narrow bands oscillating their concentrations (Fig. 6b-d). The oscillatory zoning pattern of $\mathrm{Al}$ was consistent with that of $\mathrm{Ti}$, but was antithetic to that of Fe (Fig. 6e). In the X-ray map, only $\mathrm{Al}$ showed the heterogeneous elemental distribution of the blue agate sample (Fig. 6f). Although the resolution of image was much poorer, its distribution pattern resembled that of equivalent quantitative map particularly in the outer part of the sample, but not in the inner part (Fig. 6b, f).

\section{Discussion}

Aluminum was the most abundant trace element in both agate samples and also showed the widest variation in concentration ranging from several thousands of parts per million to hundreds of parts per million, with sharp boundaries between the compositionally distinct bands (Figs. 5b and 6b). The compositional variation and rhythmic banding of $\mathrm{Al}$ in the samples are typical for silica precipitation at low temperatures below $300{ }^{\circ} \mathrm{C}$ (Rusk et al. 2011). Agates commonly contain considerable amounts of mineral and fluid inclusions possibly responsible for their different coloration (Götze et al. 2001). The quantitative Fe and Mn elemental maps and microscopic images of the colorful agate sample clearly showed spot-shaped numeral mineral inclusions definitely changing from Fe oxide/hydroxide in the inner half to Mn-bearing hollandite in the outer half (Fig. 5c, e). The distribution of Fe ions was highlighted in either $\mathrm{Fe}$ oxide/hydroxide inclusions or chalcedony structure as a substitute for $\mathrm{Si}^{4+}$ particularly in the inner half (Fig. 5c), whereas that of $\mathrm{Mn}$ ions was mainly restricted to hollandite inclusions in the outer half (Fig. 5e). The distribution patterns indicate that the valence state of Mn remained tri- and tetra-valent during the silica precipitation of outer half and further suggest that redox conditions and/or fluid compositions might change significantly between two distinct growth zones (Barnaby and Rimstidt 1989; Götze et al. 2012). The change is also reflected by the different coloration of two growth zones in the colorful agate sample from pale orange-red brown to gray in combination with $\mathrm{Cu}$ and $\mathrm{Co}$ (Table 1; Fig. 5). On the other hand, the blue agate sample does not show conspicuous mineral inclusions. Aluminum, $\mathrm{Fe}$, and $\mathrm{Ti}$ ions were distributed in the sample as a 

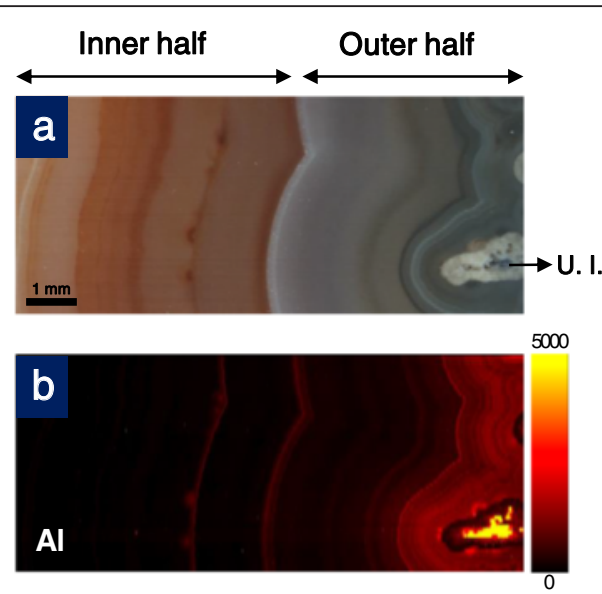

4000
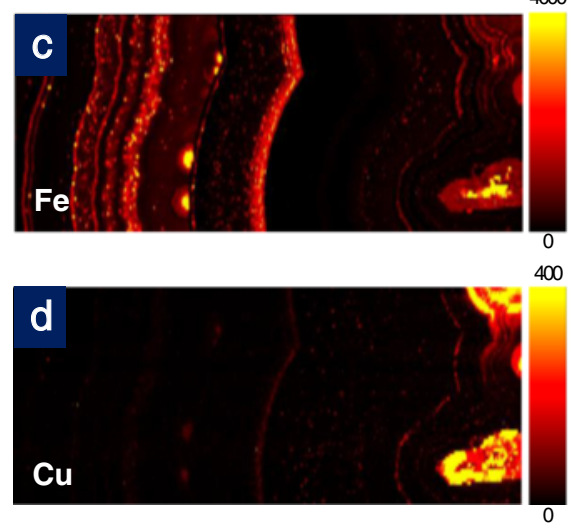
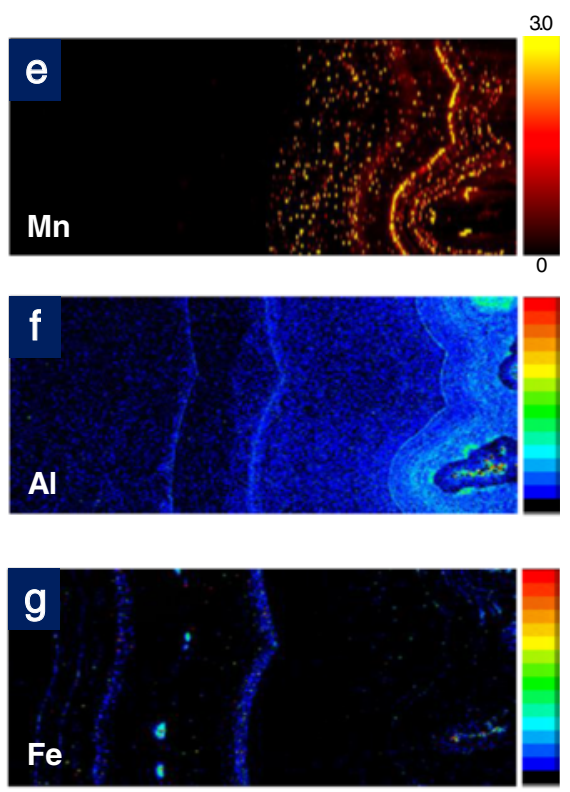

Fig. 5 The optical image, quantitative maps, and qualitative X-ray maps of the colorful agate sample. a Photomicrograph of ablated area. $\mathbf{b}-\mathbf{e}$ LA-ICP-MS quantitative maps of Al, Fe, Cu, and Mn. Scale bars represent concentrations of each element in parts per million. $\mathbf{f}$, $\mathbf{g}$ Qualitative X-ray maps of Al and Fe. U.I. unidentified material filling cavity

replacement for $\mathrm{Si}^{4+}$. The oscillatory zoning patterns of $\mathrm{Al}$, $\mathrm{Fe}$, and $\mathrm{Ti}$ were apparent in the sample (Fig. 6b-d). Such fluctuations of trace element concentrations might be associated with abundance of microcrystalline quartz (Götze et al. 2001). The partitioning of trace elements into chalcedony stronger than that into microcrystalline quartz might result in the concentration of transition metals at bluish bands.

The quantitative maps of trace elements in two agate samples show several lines of advantages on the LAICP-MS mapping technique. The quantitative $\mathrm{Mn}$ and $\mathrm{Ti}$ maps of colorful and blue agate samples, respectively, suggest that the compositional zonation of trace elements can be observed with their concentrations down to several parts per million levels (Figs. 5e and 6d). Analytical time spent for the quantitative mapping was ca. 18 h. Moggi-Cecchi et al. (2002) suggested that long counting times and special operating conditions are required to obtain X-ray distribution maps for trace elements below 1000 ppm. The maps can further be semiquantified by electron microprobe spot analyses. Rusk et al. (2008) lowered the detection limits of semi- quantitative maps of trace elements down to several tens of parts per million levels, but the amount of time spent for the mapping was ca. $90 \mathrm{~h}$ on the $500 \times 500$ pixel map size. The qualitative $\mathrm{Al} \mathrm{K \alpha}$ and Fe $\mathrm{K} \alpha \mathrm{X}$-ray maps of the colorful agate sample have reproduced the distribution patterns of trace elements similar to their quantitative maps (Fig. 5b, c, f, g), but the reproduction failed in other qualitative maps. Based upon the qualitative $\mathrm{Al} \mathrm{K \alpha} \mathrm{X}$-ray map of the blue agate, the detection limits of qualitative mapping in the study were around 100-200 ppm (Fig. 6b, f), and it took $15 \mathrm{~h}$ for a common electron microprobe equipped with four WDS to map the distribution of eight trace elements in the blue agate sample with $500 \times$ 500 pixel resolution. The potential limitations of laser ablation imaging that have commonly been mentioned lie in (1) its destructive nature with respect to other microsampling methods (Woodhead et al. 2007) and (2) its relatively large beam size resulting in relatively low spatial resolution (Ulrich et al. 2009). The ablated depth of agates has been minimized to ca. $5 \mu \mathrm{m}$ in the study by a series of parallel line scans. It is also noted that the presence and distribution of $\sim 10-\mu \mathrm{m}$-long mineral inclusions were well 

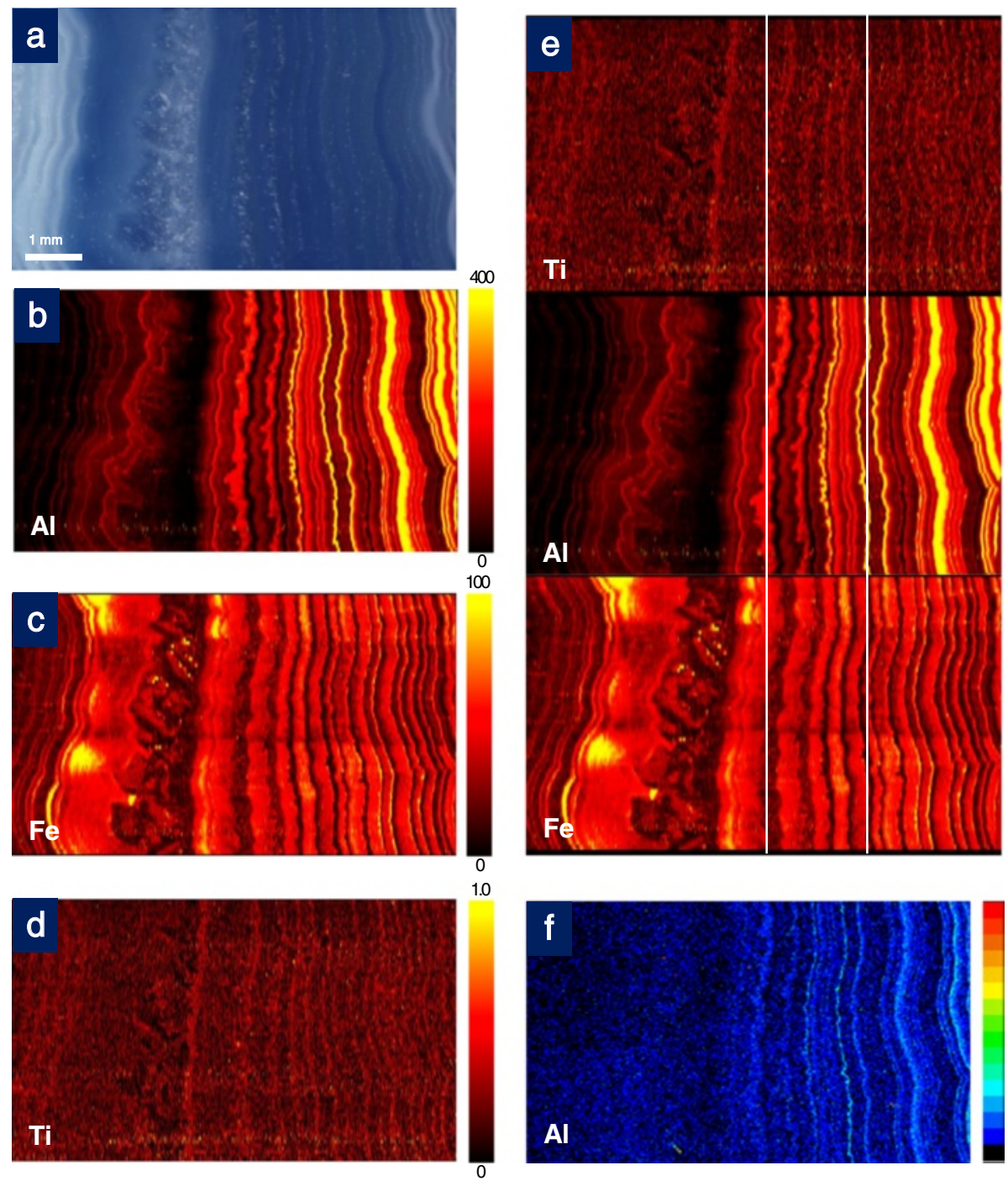

Fig. 6 The optical image, quantitative maps, and qualitative X-ray maps of the blue agate sample. a Photomicrograph of ablated area.

b-d LA-ICP-MS quantitative maps of Al, Fe, and Ti. Scale bars represent concentrations of each element in parts per million. e Composite quantitative maps with two reference white lines. $\mathbf{f}$ Qualitative X-ray map of Al

identified in the quantitative maps (Fig. 5c, e) although their size is much smaller than the beam size of laser ablation.

\section{Conclusions}

The quantitative distribution maps of trace elements in two agate samples were acquired by a series of equally long line scan and a subsequent merging of line scans with Iolite software. These maps have particularly shown the fluctuations and concentrations of trace elements in the agate samples which cannot be visualized by conventional spot analysis. The colorful agate sample showed a variation of trace elements from Fe-rich inner half to Mn-rich outer half. The quantitative maps of the blue agate sample showed a correlative distribution relationship between $\mathrm{Al}$ and $\mathrm{Ti}$, but an antithetic distribution relationship between $\mathrm{Al}$ and $\mathrm{Fe}$. The distribution patterns resulted mainly from alternating microcrystalline quartz-rich and chalcedony bands. The detection limits of quantitative maps in the study were estimated as several parts per million levels with the RSD values of ca. $10 \%$, whereas those of X-ray qualitative maps as $100-200 \mathrm{ppm}$. These results clearly demonstrate that LA-ICP-MS can provide valuable data for interpretations of compositional variations in association with microstructures, chemical/physical phase boundaries, and geological and environmental heterogeneous samples.

Competing interests

The authors declare that they have no competing interests. 


\section{Authors' contributions}

CSP and YK designed the experiment, and drafted the manuscript. Sample preparation and image processing were carried out by HC. Quantitative mapping was carried out by CSP and HSS, and qualitative mapping by KY. All the authors read and approved the final manuscript.

\section{Acknowledgements}

This work was supported by KBSI grant (T33612) to C.-S. Park. We thank anonymous reviewers for their constructive comments and suggestions.

\section{Author details}

${ }^{1}$ Division of Environmental \& Material Sciences, Korea Basic Science Institute, Cheongju 363-883, Republic of Korea. ${ }^{2}$ Department of Earth and Environmental Sciences, Chungbuk National University, Cheongju 362-763, Republic of Korea.

Received: 15 November 2015 Accepted: 6 December 2015

Published online: 17 December 2015

\section{References}

Barnaby RJ, Rimstidt JD. Redox conditions of calcite cementation interpreted from Mn and Fe contents of authigenic calcite. Geol Soc Am Bull. 1989;101: 795-804.

Durrant SF. Laser ablation inductively coupled plasma mass spectrometry: achievements, problems, prospects. J Anal At Spectrom. 1999;14:1385-403.

Fairchild IJ, Smith CL, Baker A, Fuller L, Spötl C, Mattey D, et al. Modification and preservation of environmental signals in speleothems. Earth Sci Rev. 2006;5: 105-53.

Götze J, Tichomirowa M, Fuchs H, Pilot J, Sharp ZD. Geochemistry of agates: a trace element and stable isotope study. Chem Geol. 2001;175:523-41.

Götze J, Schrön W, Möckel R, Heide K. The role of fluids in the formation of agates. Chemie der Erde. 2012;72:283-6.

Günther D, Hattendorf B. Solid sample analysis using laser ablation inductively coupled plasma mass spectrometry. Trends in Anal Chem. 2005;24:255-65.

Günther D, Heinrich CA. Enhanced sensitivity in laser ablation-ICP mass spectrometry using helium-argon mixtures as aerosol carrier-plenary lecture. J Anal At Spectrom. 1999:14:1363-8.

Günther D, Frischknecht R, Heinrich CA, Kahlert HJ. Capabilities of an argon fluoride $193 \mathrm{~nm}$ excimer laser for laser ablation inductively coupled plasma mass spectrometry microanalysis of geological materials. J Anal At Spectrom. 1997;12:939-44.

Günther D, Horn I, Hattendorf B. Recent trends and developments in laser ablation-ICP-mass spectrometry. Fresenius' J Anal Chem. 2000;368:4-14

Heaney PJ, Davis AM. Observation and origin of self-organized textures in agates. Science. 1995;269:1562-5

Heinrich CA, Pettke T, Halter WE, Aigner-Torres M, Audetat A, Günther D, et al. Quantitative milti-element analysis of minerals, fluid and melt inclusions by laser-ablation inductively-coupled-plasma mass-spectrometry. Geochim Cosmochim Acta. 2003;67:3473-96.

Hellstrom J, Paton C, Woodhead J, Hergt J. Iolite: software for spatially resolved LA-(quadrupole and MC)-ICP-MS analysis. In: Sylvester P, editor. Laser ablation ICP-MS in the earth sciences: current practices and outstanding issues. Short course series. vol 40. Ottawa: Mineralogical Association of Canada; 2008. p. 343-8.

Hinton RW. Ion microprobe trace element analysis of silicates: measurement of multi element glasses. Chem Geol. 1990;83:11-25.

Jackson SE, Longerich HP, Dunning GR, Fryer BJ. The application of laser-ablation microprobe-inductively coupled plasma-mass-spectrometry (LAM-ICP-MS) to in situ trace-element determinations in minerals. Can Mineral. 1992:30:1049-64.

Jeffries TE, Jackson SE, Longerich HP. Application of a frequency quintupled Nd: YAG source (lambda_213 nm) for laser ablation inductively coupled plasma mass spectrometric analysis of minerals. J Anal At Spectrom. 1998;13:935-40.

Koenig AE, Rogers RR, Trueman CN. Visualizing fossilization using laser ablationinductively coupled plasma-mass spectrometry maps of trace elements in Late Cretaceous bones. Geology. 2009;37:511-4.

Large R, Danyushevsky L, Hollit C, Maslennikov V, Meffre S, Gilbert S, et al. Gold and trace element zonation in pyrite using a laser imaging technique: implications for the timing of gold in orogenic and Carlin-style sedimenthosted deposits. Econ Geol. 2009;104:635-68.

Möckel R, Götze J, Sergeev SA, Kapitonov IN, Adamskaya EV, Goltsin NA, et al. Trace-element analysis by laser ablation inductively coupled plasma mass spectrometry (LA-ICP-MS): a case study for agates from Nowy Kościoł, Poland. J Siberian Federal Univ Eng Tec. 2009;2:123-38.

Moggi-Cecchi V, Cipriani C, Rossi P, Ceccato D, Rudello V, Somacal H. Trace element contents and distribution maps of chalcopyrite: a micro-PIXE study. Per Mineral. 2002;71:101-9.

Montagna P, McCulloch M, Mazzoli C, Silenzia S, Odorico R. The non-tropical coral Cladocora caespitosa as the new climate archive for the Mediterranean: high-resolution (weekly) trace element systematics. Quart Sci Rev. 2007;26: 441-62.

Müller A, Wiedenbeck M, Van den Kerkhof AM, Kronz A, Simon K. Trace elements in quartz: a combined electron microprobe, secondary ion mass spectrometry, laser-ablation ICP-MS, and cathodoluminescence study. Eur J Mineral. 2003;15:747-63.

Niemax K. Laser ablation — reflections on a very complex technique for solid sampling. Fresn J Anal Chem. 2001:370:332-40.

Norman MD, Pearson NJ, Sharma A, Griffin WL. Quantitative analysis of trace elements in geological materials by laser ablation ICP-MS: instrumental operating conditions and calibration values of NIST glasses. Geostd Newsl. 1996;20:247-61.

Paton C, Hellstrom J, Paul B, Woodhead J, Hergt J. Iolite: freeware for the visualisation and processing of mass spectrometric data. J Anal At Spectrom. 2011:22:112-21.

Polk P. Collecting rocks, gems and minerals: identification, values and lapidary uses. Fort Collins: Krause Publications; 2012.

Rusk B, Lowers H, Reed M. Trace elements in hydrothermal quartz: relationships to cathodoluminescent textures and insights into hydrothermal processes. Geology. 2008;36:547-50.

Rusk B, Koenig A, Lowers $\mathrm{H}$. Visualizing trace element distribution in quartz using cathodoluminescence, electron microprobe, and laser ablation-inductively coupled plasma-mass spectrometry. Am Mineral. 2011;96:703-8.

Sylvester P. Laser-ablation-ICP MS in the earth sciences-principles and applications. Ottawa: Mineralogical Association of Canada; 2001.

Treble P, Shelley JMG, Chappell J. Comparison of high resolution sub-annual records of trace elements in a modern (1911-1992) speleothem with instrumental climate data from southwest Australia. Earth Planet Sci Lett. 2003;216:141-53.

Ulrich T, Kamber BS, Jugo PJ, Tinkham DK. Imaging element-distribution patterns in minerals by laser ablation-inductively coupled plasma-mass spectrometry (LA-ICP-MS). Can Mineral. 2009;47:1001-12.

Woodhead JD, Hellstrom J, Hergt JM, Greig A, Maas R. Isotopic and elemental imaging of geological materials by laser ablation inductively coupled plasma-mass spectrometry. Geostd Geoanal Res. 2007;31:313-43.

\section{Submit your manuscript to a SpringerOpen ${ }^{\circ}$ journal and benefit from:}

- Convenient online submission

- Rigorous peer review

- Immediate publication on acceptance

- Open access: articles freely available online

- High visibility within the field

- Retaining the copyright to your article

Submit your next manuscript at $>$ springeropen.com 